\title{
The Effect of Six Sigma on Employees - A Case Study
}

\author{
Nagaraja Venkatesh $^{1 *}$, Sumangala Chickaswamy ${ }^{2}$ \\ and Lancy D'Souza ${ }^{3}$
}

\begin{abstract}
Irrespective of the fact that Six Sigma has been generally considered a success formula for ensuring better performance of companies, there has been little appreciation and understanding that the core of the success of Six Sigma is through a dedicated workforce. Most of the studies which highlight Critical Success Factors validate that the involvement of the entire work force contributes significantly to Six Sigma. However, in reality very few efforts have been made to look into the implications of Six Sigma on the overall welfare of the employees which is termed as People's Equity in this paper. We hold that the reverse causation has to also take place; that is, Six Sigma should improve People's Equity. This would ensure that the process is mutually reinforcing. This paper investigates the implications of Six Sigma implementation on People's Equity in a chosen automobile company. The findings suggest that both managers and employees consider that Peoples' Equity has not improved significantly after implementation of Six Sigma.
\end{abstract}

Keywords: Six Sigma, Automobile Industry, People's Equity, Manager, Worker, Benefits

\section{Introduction}

As observed by Schroeder ${ }^{12}$, many concepts like ISO 9000 Quality Management System certifications, Total Quality Management (TQM), Just-In-Time (JIT) Production Systems, Six Sigma, Manufacturing Resource Planning (MRPII), Benchmarking, etc. have been practiced and have played an important role in deciding the future of the companies belonging to different industries all over the world.

Anand et $\mathrm{al}^{3}$ have observed that quality management consists of three important components which are quality control, quality assurance and quality improvement. Another way to comprehensively look at quality

'Professor, Department of Mechanical Engineering, Canara Engineering College, Bantwal, India. Email: venksati@rediffmail.com

${ }^{2} \mathrm{Head}$ of the Department, Department of MBA, Yuvaraja's College, Mysore, India ${ }^{3}$ Professor, Department of Psychology, Maharaja's College, Mysore, India 
management is to emphasize both the means and the ends of achieving higher quality. Businesses are constantly on the lookout for ways to improve the overall quality of their goods and services to better serve their customers and improve the value of the company. To help them achieve this, companies have a burden of choosing the most effective quality improvement technique.

The concept of Six Sigma lays emphasis on cost cutting, attention to detail, continuous improvement and a more proactive approach to maximize value to the customer and improve the organization's competitive position. This concept provides the means of achieving the objectives ordained by ISO 9000 quality management system certifications. Motorola started using this methodology in all its manufacturing operations where there are repeated processes.

Over a period of time Six Sigma has developed further to be of use in non-manufacturing processes also. Today, Six Sigma can be applied to many fields such as Services, Insurance Industry, Medical Industry, and even, Call Centres. It constantly improves existing business processes by reviewing and retuning the business processes.

Schroeder ${ }^{12}$ explains that the concept of Six Sigma provides the tools and methodology to implement change in an organization. Six Sigma Projects are selected and sponsored by management to achieve strategic objectives. While some of these objectives may be discovered through analysis of ISO 9000 Corrective Action data, Six Sigma organizations often take a more proactive approach to maximize value to the customer and improve the organization's competitive position. These projects are assigned to teams consisting of process personnel who are stakeholders in the chain, and led by a trained Six Sigma Black Belt. This is a form of management oversight that ensures that the teams have the resources and authority to make necessary changes to achieve their planned objectives.

Alex ${ }^{1}$ in his research has found that the Master Black Belt who is an expert in Six Sigma tools and methods leads the team through the DMAIC methodology, (Define the projects goals, Measure the process baseline, Analyze the potential sources of variation, deploy the means to Improve the process, then finally establish a Control 
plan to standardize on the new process), and ensures the overall improved level of performance. The person is well supported by black belts and green belts. The whole team is monitored and motivated by a Champion who has the business responsibility. This rigorous methodology ensures that a complete analysis has been done to prevent the sub-optimization that occurs when critical factors have been neglected. The Control stage provides a means to measure the longer-term project results, and prevent the process personnel from returning to previous methods. This is aided by an appropriate document control system.

Galloway ${ }^{4}$ highlights the potential benefits of Six Sigma as follows:

1. Improvement of cross-functional teamwork across the entire organization;

2. Transformation of organizational culture from reactive mode to proactive mode;

3. Increased employee morale;

4. Reduced number of non-value added steps in critical business processes through systematic elimination, leading to faster delivery of service;

5. Reduction in Cost Of Poor Quality (COPQ) (costs associated with late delivery, customer complaints, costs associated with misdirected problem solving, etc.);

6. Increased awareness of different problem-solving tools and techniques, which leads to greater job satisfaction for employees; and,

7. Improved consistency level of service through systematic reduction of variability in the processes.

\section{Literature Review}

Alex ${ }^{1}$ has observed that cost of quality may reduced to a level of as much as 1 percent to 2 percent of the revenue of the company when the company moves from Three Sigma to Six Sigma. Galloway 4 empirically found that Six Sigma yields financial benefits when it is implemented properly in an organization. It is also observed that for any manufacturing enterprise there are many other benefits in Six Sigma implementation such as reduced time to market, improved 
processes, etc ${ }^{13}$. A survey of companies by Liu ${ }^{9}$ in Taiwan that included automobile, semiconductor and other related industries which had implemented ISO/TS 16949 reported that Six Sigma is a useful tool for improving the performance of companies in these had implemented ISO/TS 16949.

Rachele et $\mathrm{al}^{11}$ in their research on relationship between human factors and overall quality improvement reveal that any of the industries going for quality management systems, the service quality and customer satisfaction could be easily impaired by negative human factors, holding back overall performance. Hence, employee satisfaction is essential for improved quality and profitability. Anand, Peter, and Mohan $^{2}$ in their research have found that role of employees is very critical for achieving continuous improvement in any organization that has implemented Six Sigma. Continuing their research on importance of team work Anand, Peter, and Mohan ${ }^{3}$ report that for the success of Six Sigma projects human factors are extremely important. In addition to putting together a cohesive and motivated team, the leadership should be proficient in capturing tacit knowledge available in the team members.

We can also observe that culture has a role to play in effective implementation of Quality Management (QM) as Kull and Wacker ${ }^{8}$ find in their Study of Asian industries. They found that implementation of Six Sigma has country specific cultural values impacting effective QM investments. Those cultures where Uncertainty Avoidance (UA) is prevalent may even be more benefited by Six Sigma than others. This suggests that employees in cultures desiring predictability and law-like understanding will be motivated to frequently apply QM's systematic approaches, as in Six Sigma's improvement heuristics.

Another research by Kim, Vinodkumar, and Umakumar ${ }^{6}$ investigates the associations among different QM practices. They examine whether QM practices directly or indirectly relate to any of the five types of innovation (radical product, radical process, incremental product, incremental process, and administrative innovation). They show that QM practices are associated with innovation directly or 
indirectly. They also highlight that the importance of individual QM practices is tied to other practices. It is also very essential that a balance between the adoption of structured methods and the creation of an environment of psychological safety has to be maintained ${ }^{10}$. This means that the effectiveness of an organization is contingent on the congruence between structural and environmental (psychological) factors.

Jacobs and Morgan ${ }^{5}$ in their study of firms that have adopted Six Sigma has explored that there is a growth in sales and profitability for companies that have implemented Six Sigma. It is also observed that managers can tap the potential of their subordinates in a better way after implementing Six Sigma.

Despite the above mentioned studies the treatment of human issues and their complex relationship with quality has been scantily studied. While much importance is given to tangible factors like financial benefits, reduction of cost, improvement of sales, reduced defect rate etc. intangible human factors and their intricate relationship to sustainable quality need greater research attention. In line with this thinking we believe that it will be relevant to study People's Equity and effectiveness of quality systems implementation. We have empirically studied this in an automotive company.

\section{Objectives of the Study}

The objectives of the study are:

To investigate whether Six Sigma has influenced the improvement of people's equity like working conditions, morale and motivation level, promotion, increments, attrition rate, pride in work, etc. in an automobile industry.

To analyze whether managers and workers differ in their views towards the effect of Six Sigma on peoples' equity.

To meet the above objectives the following hypotheses were derived and tested.

$\mathrm{H}_{1}$ : Implementation of Six Sigma has positive impact on People's equity. 
$\mathrm{H}_{2}$ : Managers and workers differ significantly in their views on the effect of Six Sigma on peoples' equity.

\section{Methodology}

This survey is conducted in a manufacturing plant of an automobile company. The unit located at Bengaluru, Karnataka State, India, manufactures heavy motor vehicles and earth moving equipments. The unit employs more than 4000 employees in various departments. Six Sigma has been in practice since the last 8 years. More than 20 projects have been completed using Six Sigma. In the study, 300 employees who were part of the Six Sigma projects were surveyed for a period of three months during January 2014 to March 2014. The respondents included both managers and workers who were trained in Six Sigma implementation. Out of these 300 employees 250 belonged to worker level and 50 to the managerial level.

Questionnaire was used to measure People's Equity. The first draft of the questionnaire was validated though a two stage process involving (a) experts in six sigma not belonging to the company and (b) four black-belts working on Six Sigma projects in the unit. The final questionnaire included 27 parameters (Annexure) that defined People's Equity. Five-point Likert scale was used. Responses from employees and managers were separately examined in the light of the objectives of the study.

\section{Results and Discussions}

Improvement of people's equity in the unit through existing practices of Six Sigma was measured on a 5-point rating scale which revealed that the percentage of people who strongly disagreed were 0.49 percent, who disagreed were 15.72 percent, who could not say definitely were 23.09 percent, who agreed were 52.21 percent and finally those who strongly agreed were 8.47 percent. These results are shown in Table 1.

From Table 1 it is evident that more than 50 percent (60.68 percent - This is the average value of all 27 parameters as Peoples' equity is studied as a whole) of the respondents have accepted the fact that the current practices of Six Sigma improves people's equity. This fact has to be substantiated by statistical testing of the hypothesis. 
It is now necessary to select the appropriate type of test. For this, the normality test was conducted to select the type of test to be administered. Table 2 gives the result of K-S test for normality.

The $\mathrm{K}-\mathrm{S}$ test reveals that the distribution follows a normal curve as the significant value ( $\mathrm{P}$ value) is more than 0.05 . Further, the skewness value is -0.74 . Literature suggests that any distribution with skewness within $+/-1$ can still be considered as normal. Hence, we selected ttest for testing the hypotheses.

We have used one sample t-test to test the data collected from the respondents. The result of one sample t-test is as shown in Table 3 . The observed mean is tested against the test value as prescribed by the

Table 1: Frequency of Responses

\begin{tabular}{|l|c|}
\hline Scale parameters & Percentage \\
\hline Strongly disagree & 0.41 \\
\hline Disagree & 16.72 \\
\hline Can't say & 22.89 \\
\hline Agree & 53.21 \\
\hline Strongly agree & 6.57 \\
\hline
\end{tabular}

Table 2: Result of Kolmogorov-Smirnov Test of normality

\begin{tabular}{|l|c|}
\hline Normal Parameters & $\begin{array}{c}\text { Values of K-S test on } \\
\text { Peoples' equity }\end{array}$ \\
\hline Mean & 98.6557 \\
\hline Std. Deviation & 11.89539 \\
\hline P value & .057 \\
\hline Skewness & -0.74 \\
\hline
\end{tabular}

Table 3: Mean Observed and Expected Values on Peoples' Equity and Results of One Sample t-test

\begin{tabular}{|l|c|c|c|c|c|c|}
\hline Parameter & N & $\begin{array}{c}\text { Observed } \\
\text { value of } \\
\text { Mean }\end{array}$ & $\begin{array}{c}\text { Std. } \\
\text { Deviation }\end{array}$ & $\begin{array}{c}\text { Expected } \\
\text { value of } \\
\text { Mean }\end{array}$ & t-value & p-value \\
\hline $\begin{array}{l}\text { Peoples' } \\
\text { Equity }\end{array}$ & 300 & 95.1 & 4.81 & 97.2 & -2.392 & $0.023^{* *}$ \\
\hline
\end{tabular}

** Significant at 5 percent level 
company. Company, where the research is done has a common practice of accepting the results of a survey if the mean value is 3.6 or more on a five point scale. In this research, Peoples' Equity is measured using 27 factors. Using the norm of 3.6 on a five point scale we have computed the expected value of 27 factors collectively to be $97.2(3.6 * 27$ factors).

From Table 2, we can observe that the calculated mean value (95.1) is less than the test value (97.2). We need to check whether this difference of means is statistically significant or not. This can be tested by comparing the Significance value (Sig. $=0.023$ ) with that of $\mathrm{p}$ value $(0.05)$ as shown in Table 3. In other words, one sample t-test showed that this was a statistically significant difference, t $(249)=-2.392, \mathrm{p}<0.05$.

We can observe that significance value is less than the p value. Hence the difference of means is significant beyond 5 percent and it is not by chance. Thus we can infer that as per the opinion of the respondents of the automobile industry, the Six Sigma implementation has not significantly contributed towards peoples' equity. This results in rejection of the hypothesis $\mathrm{H}_{1}$.

\section{Congruence in Views between Managers and Workers}

After understanding the interrelationship between Six Sigma and people's equity at this automobile industry, and proving that people's equity and Six Sigma implementation are independent of each other, tests were conducted to investigate whether a difference exists between opinions of workers with that of opinions of managers with respect to effect of Six Sigma on peoples' equity. The Table 4 gives the details of values of means of two groups viz. managers and workers.

We find that the calculated value of mean for two groups is very close to each other. This indicates that there is not much difference of opinion

Table 4: Group Statistic table for Benefits of Six Sigma and Result of Independent Sample $\mathrm{t}$-test

\begin{tabular}{|l|c|c|c|c|c|c|}
\hline Variable & $\begin{array}{c}\text { Designation } \\
\text { of respondent }\end{array}$ & $\mathbf{N}$ & Mean & $\begin{array}{c}\text { Std. } \\
\text { Deviation }\end{array}$ & t-value & P-value \\
\hline \multirow{2}{*}{$\begin{array}{l}\text { Peoples' } \\
\text { equity }\end{array}$} & Worker & 250 & 94.95 & 5.74433 & -.238 & 0.814 \\
\cline { 2 - 6 } & Manager & 50 & 95.4 & 2.17051 & & \\
\hline
\end{tabular}


between the groups. This can be substantiated by checking whether this difference is statistically significance or not. The significance value (0.814), as shown in Table 4 , is greater than the $\mathrm{p}$ value $(0.05)$. To put in other words, a difference found between the managers and the workers on the effect of Six Sigma on peoples' equity is not significant $(p=0.814)$. Therefore, we infer that the views of both managers and workers are same indicating they both believe that the Six Sigma implementation has not significantly contributed towards the improvement of peoples' equity at the automobile company studied.

Normally, it is felt that since managers and workers belong to two different classes of workforce, they differ in their views. But, in this case it is statistically proved that their views on the effect of Six Sigma on peoples' equity are same. Both groups felt that the contribution of Six Sigma on improvement of peoples' equity is not significant. This disproves our second hypothesis.

\section{Conclusion}

Six Sigma is one of the quality management systems which any organization irrespective of its nature wish to implement to reap the benefits thereafter. Most studies on imnplementation of Six Sigma consider the tangible factors like financial benefits, improved productivity, reduced defect rate etc. However, it is equally important to consider how such implementation benefits the employees. Rachele et $\mathrm{al}^{11}$ have observed that the overall productivity and quality of the products are directly linked to human factors. Anand, Peter, and Mohan ${ }^{3}$ explain that a motivated team can achieve a lot more than an unmotivated team. Similarly, Kull and Wacker ${ }^{8}$ explain how the consideration of culture of people generate positive impact.

The study we conducted at the automobile company was undertaken to understand the implication of Six Sigma on people's equity. The purpose of the paper was to throw more light on human factor and the psychological benefits accrued from Six Sigma implementation.

In the first stage of the study, implication of Six Sigma on people's equity was studied, and contrary to expectations the study revealed that people's equity had not improved after its implementation. In the 
second stage the point of view of workers and managers were studied. The results from the two groups show that their view on Six Sigma implementation do not differ significantly.

This study opens up opportunities for studying impact of six sigma and not only automotive industry but also other similar industries. The findings of this study put the onus on top management to improve peoples' overall equity in their respective organisations.

\section{References}

Alex, L. (2007). Deployment of Six Sigma in SME's. Retrieved from http://www.EzineArticles.com

Anand, G., Ward, P. T., \& Tatikonda M. V. (2009). Dynamic capabilities through continuous improvement infrastructure. Journal of Operations Management, 27, 444-461.

Anand, G., Ward, P. T., \& Tatikonda M. V. (2010). Role of explicit and tacit knowledge in Six Sigma projects: An empirical examination of differen $\neg$ tial project success. Journal of Operations Management, 28, 303-315.

Galloway, R. M. (2008). Six Sigma implementation: An empirical analysis of critical success factors and performance outcomes. Retreived from http://www. EzineArticles.com

Jacobs, B. W., \& Morgan, S. (2012). Six Sigma adop $\neg$ tion: Operating performance impacts and contextual drivers of success. Journal of Operations Management, 30, 437-453.

Kim, D. Y., Vinodkumar, \& Umakumar. (2012). Rela $\neg$ tionship between quality management practices and innovation. Journal of Operations Management, 30, 295315.

Kothari, C. (2009). Research methodology, methods and technique. New Delhi: New Age International Publications.

Kull, T. J., \& Wacker, J. G. (2010). Quality management effectiveness in Asia: The influence of culture. Journal of Operations Management, 28, 223-239.

Liu, C. H. (2009). Effect of ISO/TS16949 on Six Sigma: the empirical case of Taiwanese automobile and related industries. Total Quality Management and Business Excellence, 20(11), 1229-1245.

Nair, A., Malhotra, M. K., \& Ahire, S. L. (2010). Toward a theory of managing Context in Six Sigma process-improvement projects: An action research investigation. Journal of Operations Management, 29, 529-548. 
Yee R. W. Y., Yeung A. C. L., \& Cheng T. C. E. (2008). The impact of employee satisfaction on qual $\neg$ ity and profitability in high-contact service industries. Journal of Operations Management, 26, 651-668.

Schroeder, R. L. (2008). Six Sigma: definition and underlying theory. Journal of Operations Mangement, 26, 536-554.

Shrivastava, T. N., \& Tushar N. D. (2008). Six Sigma - A New Direction to Quality and productivity Management, World Congress on Engineering and Computer Science, San Fransisco, 22-24.

Zikmund, W. G. (2009). Business research methods. South Western Publications. 


\section{Annexure}

\section{Parameters Used to Define Peoples' Equity}

1. The senior management always gives the required resources to complete the project under consideration.

2. The leadership style is helping the implementation of Six Sigma to improve the performance of industry.

3. Management takes decisions based on facts, driven by data and not on assumptions.

4. Employees are given more support to participate in decision making process.

5. Employees are encouraged to learn new things

6. There is increased awareness of various problem solving tools and techniques of Six Sigma among workers.

7. The workers are given training and education on a continuous basis.

8. New incentive programs have been introduced.

9. Human values are treated very highly

10. Interpersonal relationships have improved because of Six Sigma

11. Employees are told about the happenings in the company.

12. Employees contributions are well supported, recognized, and rewarded in the new system.

13. Six Sigma has improved the morale of the employees

14. The communication among workers has improved.

15. The implementation of Six Sigma has improved the working culture.

16. Employees take pride while participating in Six Sigma projects.

17. After Six Sigma implementation the whole working culture within the company has changed.

18. The feedback from the customers are treated positively by the management

19. Employees are encouraged to get the feedback from customers

20. Employees share their knowledge to ensure everyone understands the benefit of that knowledge

21. There is a companywide commitment to follow Six Sigma.

22. The employee retention has improved after Six Sigma implementation.

23. The employees have become more open for change.

24. The changes are continuously monitored.

25. Six Sigma has resulted in increased commitment from the suppliers also

26. I enjoyed the implementation of Six Sigma

27. Given an option I wish to work always in Six Sigma company 